\title{
An Acute Care for Elders Quality Improvement Program for Complex, High-Cost Patients Yields Savings for the System
}

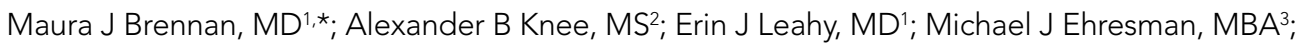 \\ Heidi-Ann Courtney, PA-C ${ }^{1}$; Patricia Coffelt, MSN, RN-BC ${ }^{4}$; Mihaela S Stefan, MD, PhD ${ }^{1,5}$
}

\begin{abstract}
'Department of Medicine, Baystate Health, Springfield, Massachusetts; ${ }^{2}$ Baystate Medical Center Office of Research, Springfield, Massachusetts; ${ }^{3}$ Clinical Financial and Decision Support, Baystate Medical Center, Springfield, Massachusetts; ${ }^{4}$ Department of Nursing, Baystate Medical Center, Springfield, Massachusetts; ${ }^{5}$ Institute for Healthcare Delivery and Population Science, University of Massachusetts Medical School-Baystate, Springfield, Massachusetts.
\end{abstract}

BACKGROUND: Acute Care for Elders (ACE) programs improve outcomes for older adults; however, little is known about whether impact varies with comorbidity severity.

OBJECTIVE: To describe differences in hospital-level outcomes between ACE and routine care across various levels of comorbidity burden.

DESIGN: Cross-sectional quality improvement study. SETTING: A 716-bed teaching hospital.

PARTICIPANTS: Medical inpatients aged $\geq 70$ years hospitalized between September 2014 and August 2017.

INTERVENTION: ACE care, including interprofessional rounds, geriatric syndromes screening, and care protocols, in an environment prepared for elders

MEASUREMENTS: Total cost, length of stay (LOS), and 30-day readmissions. We calculated median differences for cost and LOS between ACE and usual care and explored variations across the distribution of outcomes at the 25th, 50th, 75th and 90th percentiles. Results were also stratified across quartiles of the combined comorbidity score.

RESULTS: A total of 1,429 ACE and 10,159 non-ACE patients were included in this study. The mean age was 81 years, $57 \%$ were female, and $81 \%$ were white. ACE patients had lower costs associated with care ranging from $\$ 171$ at the 25 th percentile to $\$ 3,687$ at the 90 th percentile, as well as lower LOS ranging from 0 days at the 25th percentile to 1.9 days at the 90 th percentile. After stratifying by comorbidity score, the greatest differences in outcomes were among those with higher scores. There was no difference in 30-day readmission between the groups.

CONCLUSION: The greatest reductions in cost and LOS were in patients with greater comorbidity scores. Risk stratification may help hospitals prioritize admissions to ACE units to maximize the impact of the more intensive intervention. Journal of Hospital Medicine 2019;14:527533. Published online first May 10, 2019. (C) 2019 Society of Hospital Medicine n 2016, 15.2\% of older Americans were hospitalized compared with $7 \%$ of the overall population and their length of stay (LOS) was 0.7 days greater. ${ }^{1}$ Geriatric hospitalizations frequently result in complications, functional decline, nursing home transfers, and increased cost..$^{2-4}$ This pattern of decline has been termed "hospitalitis" or dysfunctional syndrome ${ }^{5,6}$ Hospitals need data-driven approaches to improve outcomes for elders. The Acute Care for Elders (ACE) program, which has been in existence for roughly 25 years, is one such model. ACE features include an environment prepared for older adults, patient-centered care to prevent functional and cognitive decline, frequent medical review to prevent iatrogenic

\footnotetext{
*Corresponding Author: Maura J Brennan, MD; E-mail: maura.brennan@bhs. org; Telephone: 413-794-3147

Additional Supporting Information may be found in the online version of this article.
}

Received: October 4, 2018; Revised: February 28, 2019;

Accepted: March 5, 2019

() 2019 Society of Hospital Medicine DOI 10.12788/jhm.3198 injury or new geriatric syndromes, and early discharge and rehabilitation planning to maximize the likelihood of return to the community. Although published data vary somewhat, ACE programs have robust evidence documenting improved safety, quality, and value. ${ }^{8-15} \mathrm{~A}$ recent meta-analysis found that $\mathrm{ACE}$ programs decrease LOS, costs, new nursing home discharges, falls, delirium, and functional decline ${ }^{16}$ However, of the 13 ACE trials reported to date, only five were published in the last decade. Recent rising pressure to decrease hospitalizations and reduce LOS has shifted some care to other settings and it is unclear whether the same results would persist in today's rapid-paced hospitals.

ACE programs require enhanced resources and restructured care processes but there is a notable lack of data to guide patient selection. Admission criteria vary among the published reports, and information on whether comorbidity burden impacts the magnitude of benefit is scarce. One ACE investigator commented, "We were not able to identify a subgroup of patients who were most likely to benefit." 17 Not all hospitalized older adults can receive ACE care, and some units have closed due to financial and logistic pressures; thus, criteria to 
TABLE 1. Patient Characteristics

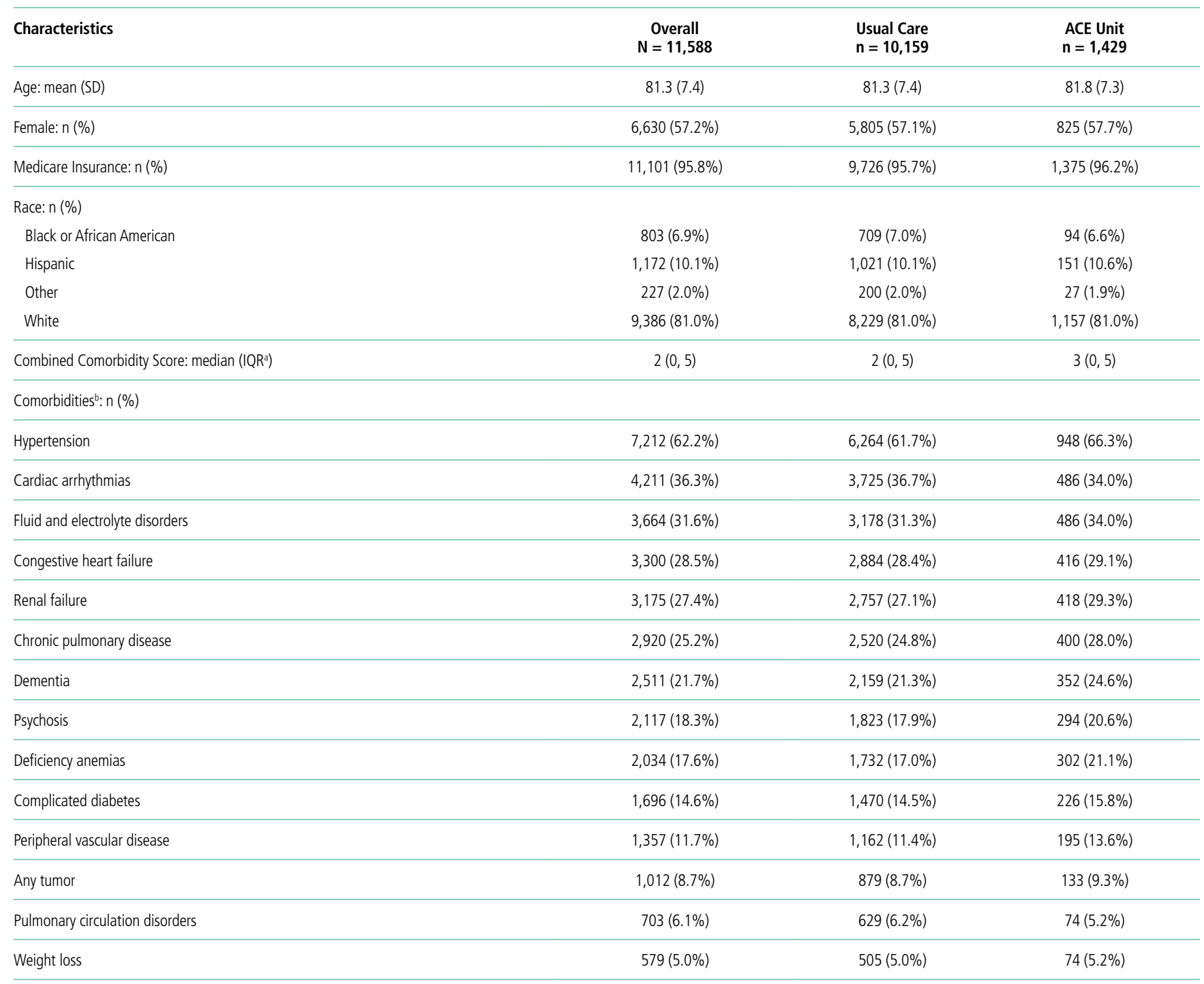

anterquartile Range: 25 th percentile to the 75 th percentile.

${ }^{b}$ Comorbidities $<5 \%$ are not listed in the table: alcohol abuse, coagulopathy, hemiplegia, HIV/AIDS, liver disease, and metastatic cancer.

Abbreviations: IQR, interquartile range; SD, standard deviation.

target this scarce resource are urgently needed. Our hospital implemented an ACE program in 2014 and we have measured and internally benchmarked important quality improvement metrics. Using this data, we conducted an exploratory analysis to generate hypotheses on the differential impact across the spectrum of cost, LOS, 30-day readmissions, and variations across quartiles of comorbidity severity.

\section{METHODS}

\section{Setting and Patients}

In September 2014, our 716-bed teaching hospital in Springfield, Massachusetts launched an ACE program to improve care for older adults on a single medical unit. The program succeeded in engaging the senior leadership, and geriatrics was identified as a priority in Baystate's 5-year strategic plan.
ACE patients $\geq 70$ years were admitted from the emergency department with inpatient status. Patients transferred from other units or with advanced dementia or nearing death were excluded. Core components of the ACE program were derived from published summaries (see supplementary material)., ${ }^{76}$

\section{Interprofessional "ACE Rounds"}

Interprofessional ACE Rounds occurred every weekday. As one ACE analyst has noted, "the interdisciplinary team...ensures that the multifactorial nature of functional decline is met with a multicomponent plan to prevent it." ${ }^{18}$ Rounds participants shifted over time but always included a geriatrics physician assistant (PA) or geriatrician (team leader), a pharmacist, staff nurses, and a chaplain. The nurse educator, dietician, research assistant, and patient advocate/volunteers attended intermit- 
TABLE 2. Differences in Total Cost and Length of Stay for Usual Care Versus ACE Units

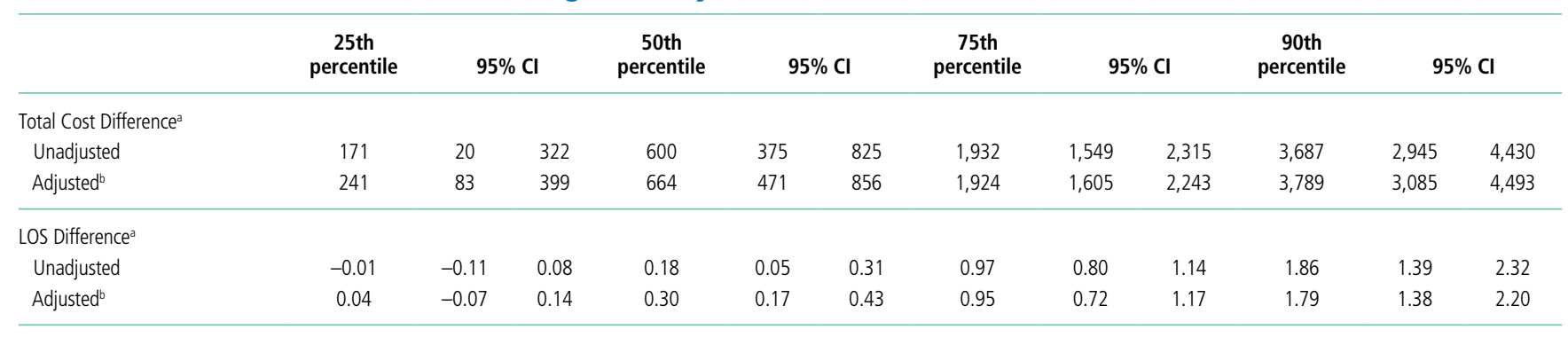

a Quantile regression using clustered standard errors to account for repeated patient visits. Estimates use ACE as the referent group.

${ }^{b}$ Adjusted for age and combined comorbidity score.

Abbreviation: ACE, acute care for elders; LOS, length of stay.

tently. Before rounds, the PA reviewed the admission notes for new ACE patients. Initially, rounds were lengthy and included nurse coaching. Later, nurses' presentations were structured by the SPICES tool (Sleep, Problems with eating/feeding, Incontinence, Confusion, Evidence of falls, Skin Breakdown $)^{19}$ and tracking and reporting templates. Coaching and education, along with conversations that did not require the full team, were removed from rounds. Thus, the time required for rounds declined from about 75 minutes to 35 minutes, which allowed more patients to be discussed efficiently. This change was critical as the number of ACE patients rose following the shift to the larger unit. The pharmacist reviewed medications focusing on potentially inappropriate drugs. Following rounds, the nurses and pharmacist conveyed recommendations to the hospitalists.

\section{Patient-Centered Activities to Prevent Functional and Cognitive Decline}

Project leaders coached staff about the importance of mobility, sleep, and delirium prevention and identification. The nurses screened patients using the Confusion Assessment Method (CAM) and reported delirium promptly. Specific care sets for ACE patients were implemented (see supplementary material).

The project was enhanced by several palliative care components, ie tracking pain, noting psychiatric symptoms, and considering prognosis by posing the "Surprise Question" during rounds. ${ }^{20}$ ("Would you be surprised if this patient died in the next year?"). As far as staffing and logistics allowed, the goals of care conversation were held by a geriatrics PA with patients/ families who "screened in."

\section{Prepared Environment}

The ACE program's unit was remodeled to facilitate physical and cognitive functioning and promote sleep at night (quiet hours: 10 PM-6 AM).

In accordance with quality improvement processes, iterative shifts were implemented over time in terms of checklist, presentation format, timing, and team participation. In December 2016, the program relocated to a unit with 34 ACE beds and 5 end-of-life beds; this move markedly increased the number of eligible ACE patients.

\section{Study Design, Data Source, and Patients}

Since we were implementing and measuring our ACE program with a quality improvement lens, we chose a descriptive cross-sectional study design to generate hypotheses regarding our program's impact compared to usual care. Using a hospital-wide billing database (McKesson Performance Analytics, v19, Alpharetta, Georgia) we sampled inpatients aged $>70$ years with a medical Diagnosis Related Group (DRGs) admitted through the emergency department and discharged from a medical unit from September 22, 2014 to August 31, 2017. These criteria mirrored those in the ACE unit. Older adults requiring specialized care (eg, those with myocardial infarct) were excluded, as were those with billing codes for mechanical ventilation, admission to critical care units, or discharge to hospice. Because one of our outcomes was readmission, we excluded patients who died during hospitalization. Patient characteristics collected included demographics and insurance category. To evaluate comorbidity burden, we collected ICD-9/ICD-10 diagnostic codes and generated a combined comorbidity score as described by Gagne, et al. ${ }^{21}$ This score was devised to predict mortality and 30-day readmissions and had better predictive ability in elders than the Elixhauser or Charlson scores. Scores ranged from -2 to 26 , although values $>20$ are rare.

\section{Exposure}

Subjects were categorized as either discharged from the ACE or discharged from usual care. ACE discharges were tracked daily on a spreadsheet that was linked into our sample of eligible subjects.

\section{Outcomes}

Total cost of hospitalization (direct plus indirect costs), LOS, and all-cause 30-day readmissions were queried from the same billing database.

\section{Statistical Analysis}

As this study was a quality improvement project, analyses were descriptive and exploratory; no statistical hypothesis testing was conducted. We initially evaluated subject characteristics and comorbidities across study groups to determine 


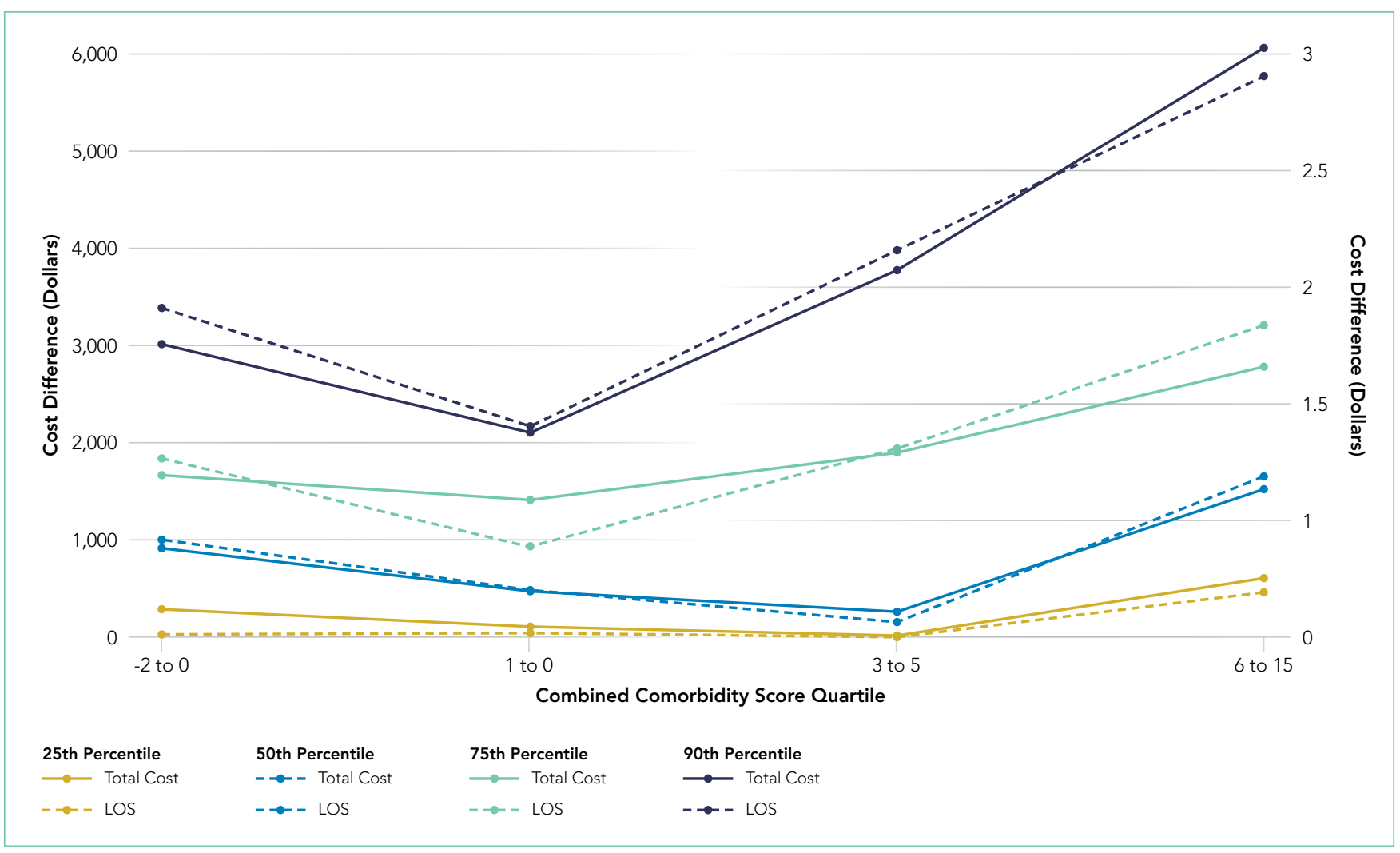

FIG 1. Differences in Total Cost and Length of Stay for Usual Care versus ACE Units Stratified by Comorbidity Severity

Abbreviations: $\mathrm{ACE}$, acute care for elders; LOS, length of stay.

group balance and comparability using means and standard deviations for continuous data and frequencies and percentages for categorical data. To analyze total cost and LOS, we utilized quantile regression with clustered standard errors to account for clustering by patient. We calculated the median difference between hospitalization cost and LOS for usual care versus ACE patients (with ACE as the referent group). To explore variations across the distributions of outcomes, we determined differences in cost and LOS and their 95\% confidence intervals at the 25th, 50th, 75th, and 90th percentiles. Thirty-day readmission risk was estimated using a generalized estimating equation model with a logit link and binomial family. Readmission risk is presented along with $95 \%$ confidence intervals. For all models, we initially evaluated change over time (by quarter). After establishing the absence of time trends, we collapsed results into a comparison of usual care versus ACE care. Model estimates are presented both unadjusted and adjusted for age and comorbidity score. Following our initial analyses of cost, LOS, and 30-day readmission risk; we explored differences across quartiles of combined comorbidity scores. We used the same unadjusted models described above but incorporated an interaction term to generate estimates stratified by quartile of comorbidity score. We performed two additional analyses to evaluate the robustness of our findings. First, because hemiplegia prevalence was higher in the usual-care group than in the ACE group and can result in higher cost of care, we repeated the analysis after excluding those patients with hemiplegia. Second, because we were unable to control for functional capacity in the entire sample, we evaluated group differences in mobility for a subsample obtained prior to October 2015 using ICD-9 diagnostic codes, which can be considered surrogate markers for mobility. ${ }^{22}$ The results of our first analysis did not substantively change our main findings; in our second analysis, groups were balanced by mobility factors which suggested that confounding by functional capacity would be limited in our full sample. The results of these analyses are reported in the supplemental material.

Analysis was completed using Stata v15.1 (StataCorp, LP College Station, Texas). The Baystate Medical Center Institutional Review Board determined that the initiative was quality improvement and "not research."

\section{RESULTS}

A total of 13,209 patients met the initial inclusion criteria; 1,621 were excluded, resulting in a sample of 11,588 patients. Over the 3-year study period, 1,429 (12.3\%) were discharged from ACE and 10,159 (87.7\%) were discharged from usual care. The groups were similar in age, sex, race and insurance status. Compared with the usual-care group, ACE patients had a higher median comorbidity score (3 vs 2 for usual care) and higher rates for anemia, dementia, fluid and electrolyte disorders, hypertension, and chronic obstructive pulmonary disease (COPD). However, ACE patients had lower rates of hemiplegia 


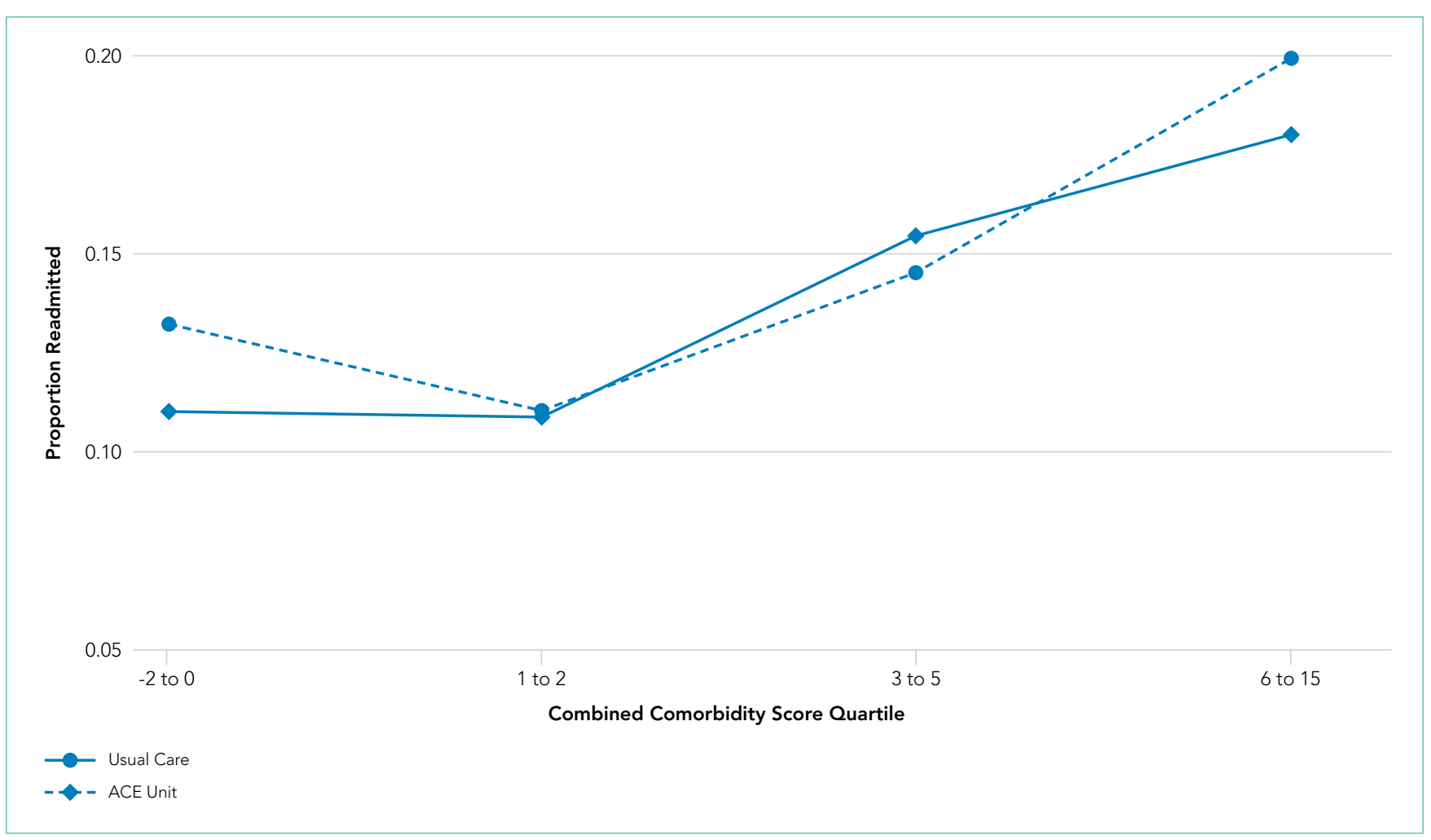

FIG 2. Risk of 30-Day Readmission for Usual Care and ACE Units Stratified by Comorbidity Severity

Abbreviation: $A C E$, acute care for elders.

(0.9\% vs $3 \%)$, arrhythmias, and pulmonary circulation disorders than those with usual care (Table 1).

The median cost per ACE patient was slightly lower at $\$ 6,258$ (interquartile range [IOR] $=\$ 4,683-\$ 8,547)$ versus $\$ 6,858(I \mathrm{R}=$ $\$ 4,855-\$ 10,478$ ) in usual care. Across the cost distribution, the ACE program had lower costs than usual care; however, these differences became more pronounced at the higher end of the distribution. For example, compared with the ACE group, the usual-care group's unadjusted cost difference was $\$ 171$ higher at the 25th percentile, $\$ 600$ higher at the median, $\$ 1,932$ higher at the 75th percentile, and $\$ 3,687$ higher at the 90th percentile. The ACE median LOS was 3.7 days (IOR = 2.7-5.0) compared with 3.8 days $(I Q R=2.7-6.0)$ for non-ACE patients. Similar to cost, LOS differences rose at higher percentiles of the distribution, with shorter stays for the ACE patients within each grouping. Compared with the ACE group, the unadjusted LOS difference for usual-care patients ranged from 0 days at the 25th percentile to 0.2 day longer at the median, 1.0 day longer at the 75th percentile, and 1.9 days longer at the 90th percentile. For both cost and LOS models, estimates remained stable after adjusting for age and combined comorbidity score (Table 2).

We explored the impact of increasing comorbidity burden on these outcomes using the following quartiles of the combined comorbidity score: -2 to 0 (387 ACE vs 3,322 usual-care patients), 1 to 2 (264 ACE vs 1,856 usual-care patients), 3 to 5 (476 ACE vs 2,859 usual-care patients), and 6 to 15 (301 ACE vs 2,122 usual-care patients). It was not surprising that cost and LOS paralleled each other, with the greatest cost and LOS benefits in the highest quartile of the combined comorbidity score (Figure 1). For example, at the 90th percentile, the cost difference approached $\$ 6,000$ higher for the usual-care group in the top quartile of combined comorbidity score compared with nearly $\$ 3,000$ higher for the lowest quartile. Similarly, at the 90th percentile, LOS for usual-care patients was 2.9 days longer at the top quartile compared with 1.7 days longer at the lowest quartile.

The all-cause 30-day readmission risk was similar for both groups, with an absolute risk difference of $-0.7 \%(95 \% \mathrm{Cl}=$ $-2.6 \%$ to $1.3 \%$ ). Adjustment for age and comorbidity score did not substantially change this result. Following stratification by quartile of combined comorbidity scores, we observed similar readmission risks at each quartile (Figure 2).

\section{DISCUSSION}

This quality improvement initiative evaluated which ACE admissions yielded the greatest value and found the largest reductions in LOS and cost in patients with the greatest comorbidity scores (frequently referred to as "high need, high cost"). ${ }^{23,24}$ Based on prior literature, we had anticipated that moderate risk patients would show the maximum benefit. ${ }^{15,25}$ In contrast to our findings, a University of Alabama (UAB) ACE program subgroup analysis using the CMS Case Mix Index (CMI) found a cost reduction for patients with low or intermediate CMI scores but not for those with high scores. ${ }^{15}$ The Hospital Elder Life Program (HELP) has yielded maximal impact for patients at moderate risk for delirium. ${ }^{26}$ Our results 
are supported by a University of Texas, Houston, study revealing lower LOS and cost for ACE patients, despite high CMI scores and endemic frailty, although it did not report outcomes across a range of comorbidities or costs. ${ }^{27}$ Our results may be determined by the specific characteristics of the Baystate ACE initiative. Our emphasis on considering prognosis and encouraging advance care planning could have contributed to the improved metrics for more complicated patients. It is possible that patients with high comorbidity burden were more likely to screen in with the surprise question, leading to more frequent goals of care discussions by the hospitalists or geriatrics team, which, in turn, may have resulted in less aggressive care and consequently lower costs. The emphasis on prognosis and palliative care was not a feature of the UAB or Texas studies. Additional components, such as the delirium screening and the presence of volunteer advocates, could also have impacted the results. Our tiered approach during rounds with rapid reviews for most patients and longer discussions for those at highest risk may have further contributed to the findings. Finally, although we did not track the recommendation acceptance rate for the entire study period, in the first nine months of the project, 9,325 recommendations were made with an acceptance rate of $>85 \%$. We previously reported a similar acceptance rate for medication recommendations. ${ }^{28}$ Another factor contributing to our results may be the ways in which we categorized patients and calculated costs. We used the Gagne combined comorbidity score, which includes only prior conditions, ${ }^{21}$ the UAB study used $\mathrm{CMI}$, which includes severity of presenting illness and complications, as well as baseline comorbidities. We also compared total cost, while UAB reported variable direct cost.

This study has a number of limitations. First, it was conducted at a single site and may not apply to other hospitals. Second, as a quality improvement program, its design, processes, and personnel evolved over time, and, as in any multicomponent initiative, the effect of individual factors on the outcomes is unknown. Third, this is an observational study with the aim of generating hypotheses for more rigorous studies in the future and residual confounding factors may exist despite efforts to adjust for variables present in an administrative database. Thus, we were unable to completely adjust for potentially important social factors, presence of delirium, or baseline functional status.

To our knowledge, this study is the first report on the differential impact of comorbidity scores and cost distribution on ACE total cost and LOS reductions. Despite its limitations, it contributes to the existing literature by suggesting that the Gagne comorbidity score can help identify which admissions will yield the greatest value. The Gagne score could be calculated at admission using the ePrognosis risk calculator or incorporated and automated in the EMR. ${ }^{29}$ Many health systems are reluctant to designate beds for specific subpopulations since doing so decreases flexibility and complicates the admission process. A dynamic tension exists between increasing income streams now and generating future savings by supporting initiatives with upfront costs. Other successful acute care geriatrics programs, such as NICHE, ${ }^{30} \mathrm{HELP}_{1}^{31} \mathrm{MACE}^{32}$ and consultation teams, exist. ${ }^{33}$ Studies reporting the outcomes of combining ACE units with these other approaches in a "portfolio approach" will inform the design of the most efficient and impactful programs. ${ }^{34}$ Scrupulous attention to symptom control and advance care planning are key features of our program, and, given the high prevalence of advanced serious illness in hospitalized older adults, this consideration may be critical for success.

As ACE units can only care for a small fraction of hospitalized older adults, determining which patients will maximally benefit from the structured, team-based care on ACE units is crucial. We found that the greatest impact on LOS and costs occurred in the subgroup with the highest comorbidity scores and overall cost. ACE care for the most vulnerable patients appeared to yield the greatest value for the system; thus, these older adults may need to be prioritized for admission. This improvement may enhance quality and value outcomes, maximize a scarce resource, and secure results needed to sustain the "clinician-led and data-driven" ACE model in the face of changing clinical and financial landscapes. ${ }^{35}$

\section{Acknowledgments}

All those with significant contributions to this work are included as authors.

The authors express their deep appreciation to all their Baystate collaborators, particularly to Rebecca Starr, MD, the first geriatrics medical director of the program, Ms. Virginia Chipps, RN, the program's first nurse manager, and Tasmiah Chowdhury, PharmD, the program's first pharmacist. We are also deeply grateful to those persons who provided programmatic advice and input on model ACE programs elsewhere, including Kyle Allen, MD, Michael Malone MD, Robert Palmer MD, and, especially, Kellie Flood, MD.

Disclosures: None of the authors have any existing or potential personal or financial conflicts relevant to this paper to report.

Funding: This work was supported in part by a Geriatric Workforce Enhancement Program award (grant \# U1QHP28702) from the Health Resources and Services Administration and by internal support from Baystate Health

\section{References}

1. National Hospital Survey: number and rate of hospital discharge 2010 table. 2010; https://www.cdc.gov/nchs/fastats/hospital.htm. Accessed February, 10th 2019.

2. Brennan TA, Leape LL, Laird NM, Hebert L, Localio AR, Lawthers AG, Newhouse JP, Weiler PC, Hiatt HH. Incidence of adverse events and negligence in hospitalized patients. results of the Harvard medical practice study I. N Engl J Med. 1991;324(6):370-376. https://doi.org/10.1056/NEJM199102073240604.

3. Creditor MC. Hazards of hospitalization of the elderly. Ann Intern Med. 1993;118(3):219-223

4. Levinson D. Adverse vents in hospitals: National incidence among Medicare beneficiaries; US Department of Health and Human Services, Office of the Inspector General 2010. Accessed February, 10th, 2019.

5. Palmer RM, Counsell S, Landefeld CS. Clinical intervention trials: the ACE unit. Clin Geriatr Med. 1998;14(4):831-849.

6. Landefeld CS. Foreword. In: Malone ML, Palmer MR, Capezuti E, eds. Acute Care for Elders New York Humana Press; 2014:v-xii.

7. Fox MT, Persaud M, Maimets I, O'Brien K, Brooks D, Tregunno D, Schraa E. Effectiveness of acute geriatric unit care using acute care for elders components: a systematic review and meta-analysis. J Am Geriatr Soc. 2012;60(12):2237-2245.https://doi.org/10.1111/jgs.12028.

8. Landefeld CS, Palmer RM, Kresevic DM, Fortinsky RH, Kowal J. A randomized trial of care in a hospital medical unit especially designed to improve the functional outcomes of acutely ill older patients. N Engl J Med. 1995;332(20):1338-1344. https://doi.org/10.1056/NEJM199505183322006. 9. 
Covinsky KE, King JT, Jr., Quinn LM, Siddique R, Palmer R, Kresevic DM, Fortinsky RH, Kowal J, Landefeld CS. Do acute care for elders units increase hospital costs? A cost analysis using the hospital perspective. J Am Geriatr Soc. 1997:45(6):729-734.

10. Counsell SR, Holder CM, Liebenauer LL, Palmer RM, Fortinsky RH, Kresevic DM, Quinn LM, Allen KR, Covinsky KE, Landefeld CS. Effects of a multicomponent intervention on functional outcomes and process of care in hospitalized older patients: a randomized controlled trial of Acute Care for Elders (ACE) in a community hospital. J Am Geriatr Soc. 2000;48(12):1572-1581.

11. Asplund K, Gustafson Y, Jacobsson C, Bucht G, Wahlin A, Peterson J, Blom JO, Angquist KA. Geriatric-based versus general wards for older acute medical patients: a randomized comparison of outcomes and use of resources. J Am Geriatr Soc. 2000;48(11):1381-1388.

12. Saltvedt I, Mo ES, Fayers P, Kaasa S, Sletvold O. Reduced mortality in treating acutely sick, frail older patients in a geriatric evaluation and management unit. A prospective randomized trial. J Am Geriatr Soc. 2002;50(5):792-798.

13. Jayadevappa R, Chhatre S, Weiner M, Raziano DB. Health resource utilization and medical care cost of Acute Care Elderly unit patients. Value Health. 2006;9(3):186-192. https://doi.org/10.1111/j.1524-4733.2006.00099.x.

14. Barnes DE, Palmer RM, Kresevic DM, Fortinsky RH, Kowal J, Chren MM, Landefeld CS. Acute Care for Elders units produced shorter hospital stays at lower cost while maintaining patients' functional status. Health Aff (Millwood). 2012;31(6):1227-1236. https://doi.org/10.1377/hlthaff.2012.0142.

15. Flood KL, Maclennan PA, McGrew D, Green D, Dodd C, Brown CJ. Effects of an Acute Care for Elders unit on costs and 30-day readmissions. JAMA Intern Med. 2013;173(11):981-987. https://doi.org/10.1001/jamainternmed.2013.524.

16. Fox MT, Sidani S, Persaud M, Tregunno D, Maimets I, Brooks D, O'Brien K. Acute Care for Elders components of acute geriatric unit care: systematic descriptive review. J Am Geriatr Soc. 2013;61(6):939-946. https://doi. org/10.1111/jgs.12282.

17. Palmer MR, Kresevic DM. The Acute Care for Elders unit In: Malone ML, Palmer MR, Capezuti E, eds. Acute Care for Elders New York: Humana Press 2014:92.

18. Pierluissi E, Francis D, Covinsky KE. Patient and hospital factors that lead to adverse outcomes in hospitalized elders In: Malone ML, Palmer MR, Capezuti E, eds. Acute Care for Elders New York: Humana Press 2014:42.

19. Fulmer T. How to try this: Fulmer SPICES. Am J Nurs. 2007;107(10):40-48; quiz 48-49. https://doi.org/10.1097/01.NAJ.0000292197.76076.e1.

20. Downar J, Goldman R, Pinto R, Englesakis M, Adhikari NK. The "surprise question" for predicting death in seriously ill patients: a systematic review and meta-analysis. CMAJ. 2017;189(13):E484-E493. https://doi.org/10.1503/ cmaj. 160775 .

21. Gagne JJ, Glynn RJ, Avorn J, Levin R, Schneeweiss S. A combined comorbidity score predicted mortality in elderly patients better than existing scores. J Clin Epidemiol. 2010;64(7):749-759. https://doi.org/10.1016/j.jclinepi.2010.10.004
22. Segal JB, Chang HY, Du Y, Walston JD, Carlson MC, Varadhan R. Development of a claims-based frailty indicator anchored to a well-established frailty phenotype. Med Care. 2017;55(7):716-722. https://doi.org/10.1097/ MLR.0000000000000729

23. Blumenthal D, Chernof B, Fulmer T, Lumpkin J, Selberg J. Caring for high-need, high-cost patients - an urgent priority. N Engl J Med. 2016;375(10):909-911. https://doi.org/10.1056/NEJMp1804276

24. Blumenthal D. Caring for high-need, high-cost patients: what makes for a successful care management program? . https://www.commonwealthfund. org/publications/journal-article/2016/jul/caring-high-need-high-cost-patients-urgent-priority. Accessed March, 20th 2019.

25. Ahmed NN, Pearce SE. Acute Care for the Elderly: a literature review. Popul Health Manag. 2010;13(4):219-225. https://doi.org/10.1089/pop.2009.0058.

26. Inouye SK, Bogardus ST, Jr., Charpentier PA, Leo-Summers L, Acampora D, Holford TR, Cooney LM, Jr. A multicomponent intervention to prevent delirium in hospitalized older patients. N Engl J Med. 1999;340(9):669-676. https://doi.org/10.1056/NEJM199903043400901.

27. Ahmed N, Taylor K, McDaniel Y, Dyer CB. The role of an Acute Care for the Elderly unit in achieving hospital quality indicators while caring for frail hospitalized elders. Popul Health Manag. 2012;15(4):236-240. https://doi. org/10.1089/pop.2011.0055

28. Chowdhury TP, Starr R, Brennan M, Knee A, Ehresman M, Velayutham L, Malanowski AJ, Courtney HA, Stefan MS. A quality improvement initiative to improve medication management in an Acute Care for Elders program through integration of a clinical pharmacist. J Pharm Pract. 2018:897190018786618. https://doi.org/10.1177/0897190018786618

29. Lee S, Smith A, Widera E. ePrognosis -Gagne index. https://eprognosis.ucsf. edu/gagne.php. Accessed March 20th, 2019

30. Turner JT, Lee V, Fletcher K, Hudson K, Barton D. Measuring quality of care with an inpatient elderly population. The geriatric resource nurse model. $J$ Gerontol Nurs. 2001;27(3):8-18.

31. Hshieh TT, Yang T, Gartaganis SL, Yue J, Inouye SK. Hospital Elder Life Program: systematic review and meta-analysis of effectiveness. Am J Geriatr Psychiatry. 2018;26(10):1015-1033. https://doi.org/10.1016/j.jagp.2018.06.007.

32. Hung WW, Ross JS, Farber J, Siu AL. Evaluation of the Mobile Acute Care of the Elderly (MACE) service. JAMA Intern Med. 2013;173(11):990-996. https:// doi.org/10.1001/jamainternmed.2013.478.

33. Sennour Y, Counsell SR, Jones J, Weiner M. Development and implementation of a proactive geriatrics consultation model in collaboration with hospitalists. J Am Geriatr Soc. 2009;57(11):2139-2145. https://doi.org/10.1111/ j.1532-5415.2009.02496.x.

34. Capezuti $\mathrm{E}$, Boltz M. An overview of hospital-based models of care. In: Malone ML, Palmer MR, Capezuti E, eds. Acute Care for Elders. New York: Humana Press 2014:49-68.

35. Malone ML, Yoo JW, Goodwin SJ. An introduction to the Acute Care for Elders In: Malone ML, Palmer MR, Capezuti E, eds. Acute Care for Elders New York: Humana Press 2014:1-9. 